\title{
Two passeriform birds (Aves: Passeriformes) from the Middle Miocene of Austria
}

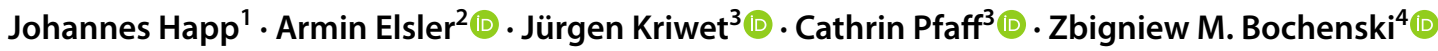

Received: 18 April 2021 / Accepted: 31 July 2021 / Published online: 26 August 2021

(c) The Author(s) 2021

\begin{abstract}
Two newly discovered specimens of passerine birds—an isolated sternum and an associated skeleton—from the upper Middle Miocene (ca. $12 \mathrm{Ma}$ ) are the oldest representatives of Passeriformes from Austria. Although the condition of the specimens prevents their accurate identification, they provide further clues on the morphological diversity of the avifauna during this period and fill gaps in the paleobiogeography of Miocene passerines. The associated skeleton represents a bird similar in size to the extant Sylvia atricapilla or Erithacus rubecula, and the delicate beak indicates that the bird fed mainly on small invertebrates and possibly also soft fruit. The isolated sternum belonged to a small thrush-sized bird and, considering the fragility of this skeletal element, is one of the best-preserved Miocene passerine sterna in the world.
\end{abstract}

Keywords Passeriformes $\cdot$ Songbirds $\cdot$ Miocene $\cdot$ Lavanttal $\cdot$ Carinthia $\cdot$ Austria $\cdot$ Micro-CT scanning

\section{Introduction}

The Lavanttal in Carinthia, southern Austria, offers an abundant and diverse record of middle Miocene fossils. A great variety of plant, invertebrate, and vertebrate fossils

Handling Editor: Mike Reich.

Zbigniew M. Bochenski

bochenski@isez.pan.krakow.pl

Johannes Happ

reptilienzoohapp@yahoo.com

Armin Elsler

armin.elsler@bristol.ac.uk

Jürgen Kriwet

juergen.kriwet@univie.ac.at

Cathrin Pfaff

cathrin.pfaff@univie.ac.at

1 Reptilienzoo Happ, Villacherstrasse 237, 9020 Klagenfurt, Austria

2 School of Earth Sciences, University of Bristol, 24 Tyndall Avenue, Bristol BS8 1RJ, UK

3 Department of Palaeontology, University of Vienna, Althanstraße 14, 1090 Vienna, Austria

4 Institute of Systematics and Evolution of Animals, Polish Academy of Sciences, Slawkowska 17, 31-016, Krakow, Poland from former terrestrial, marine, and freshwater environments were discovered and have been described so far (e.g., Grímsson et al. 2015; Nolf and Brzobohatý 2009; Prieto et al. 2019; Wank 1991). However, until now no bird fossils were reported from this important Miocene fossil locality in the Lavanttal.

In this paper we describe two new passerine specimens that were recovered from this Middle Miocene locality, contributing to our understanding of its fossil association and to the morphological diversity of birds during this period. The material comprises an isolated sternum and an almost complete but poorly preserved specimen of passerine birds.

The oldest remains of passerines in Europe come from the Oligocene of Poland, Germany and France. Five species and one nearly complete but unnamed specimen have been described so far from this period (Bochenski et al. 2011, 2013, 2018, 2021; Mayr and Manegold 2004, 2006a; Riamon et al. 2020). The unnamed specimen from France (NTLBR-014) and Crosnoornis nargizia from Poland represent Suboscines, while the other four species (Wieslochia weissi, Jamna szybiaki, Resoviaornis jamrozi and Winnicavis gorskii) could not be attributed to either Oscines or Suboscines. In addition to these new extinct species, there are several dozen other very incomplete specimens, mostly isolated bones (Bochenski et al. 2014a, b; Manegold 2008a, b; Mayr and Manegold 2006b; Mourer-Chauviré 2006; MourerChauviré et al. 1989, 2004). Some of them, dated to the late 
Oligocene, were successfully attributed to Suboscines and Oscines, which proves that the birds from these two groups coexisted in Europe (Manegold 2008a).

Many more passerines are known from the Miocene, although knowledge about them is also very fragmentary. Most new species of passerines from the Miocene of Europe (Russia, Hungary, Romania, Bulgaria, Germany, Austria, France) were described on the basis of isolated bones or their fragments (Boev 2007; Gál and Kessler 2006; Hír et al. 2001; Kessler 2013; Kessler and Hír 2012; Kessler and Venczel 2009; Manegold 2008b; Manegold et al. 2004; Volkova and Zelenkov 2018; Zelenkov 2017). In some cases, one or more other bones have been tentatively assigned to a given species. So far, the only Miocene specimen with associated bones is an almost complete passerine leg preserved on a slab found in the Northern Caucasus (Zelenkov 2018).

The new specimens described here represent the oldest passerines of Austria, and the nearly complete specimen is just the second passerine from the European Miocene which has skeletal elements preserved in articulation. This gives a unique opportunity to study a set of features on various bones not possible before and allows insights into the proportions of individual body parts.

\section{Materials and methods}

The material consists of two passerine bird remains imprinted on three claystone slabs including an isolated sternum on one slab, and a nearly complete specimen on two slabs. Both specimens come from the same locality (Lavanttal, southern Austria).

Anatomical terminology follows Baumel and Witmer (1993), if not indicated otherwise. Measurements, taken with Lux-Tool calipers on the original slabs, are given in millimeters and refer to the greatest length of the bone. The fossils are housed at the paleontological collection of the Landesmuseum Kärnten (LMK-Pal), Klagenfurt, Austria. They were compared with comparative specimens from the osteological collections of the Natural History Museum of Vienna, Austria, and the Institute of Systematics and Evolution of Animals, PAS, Kraków, Poland, and with published data on the osteology of extant and extinct Acanthisittidae, Oscines and Suboscines.

The nearly complete specimen was partially exposed mechanically by scraping off matrix covering the skeletal elements. However, due to the fragility of the preserved remains and the overlapping of individual bones and their imprints, the fossil could not be fully extracted from the matrix. The surface of both slabs was fixed with liquid glue and the specimen was investigated non-invasively by microCT scanning at the Department of Palaeontology, University of Vienna, Austria using a SkyScan/Bruker 1173 micro-CT device with a brass filter. The main slab was scanned with source voltage at $100 \mathrm{kV}$, source current at $80 \mu \mathrm{A}$, image pixel size $29.93 \mu \mathrm{m}$, exposure time $750 \mathrm{~ms}$, ring artifact correction 20, and beam hardening correction of $56 \%$. The counter slab was scanned using source voltage at $100 \mathrm{kV}$, source current at $80 \mu \mathrm{A}$, image pixel size $26.01 \mu \mathrm{m}$, exposure time $750 \mathrm{~ms}$, ring artifact correction 14, and beam hardening correction of $30 \%$. Enough contrast between the fossil and the matrix was available to separate and identify fossil bone from the matrix. Scan data were imported in Amira 5.4.5 (FEI Visualization Sciences Group) as a sequence of stacked JPGs. Segmentation was carried out using the lasso and brush tools. 3D reconstruction in Amira 5.4.5 was carried out for the right and left coracoids as well as right carpometacarpus and os carpi ulnare on the main slab, and right carpometacarpus on the counter slab.

\section{Systematic paleontology}

Aves Linnaeus, 1758

Passeriformes Linnaeus, 1758

Family, genus, and species indeterminate

Specimen \# LMK-Pal 7.451a + b

Figures 1, 2, 3, 4, 5, 6

Preservation and provenance. A fairly complete and mostly associated but poorly preserved skeleton, embedded in claystone and preserved in situ on two claystone slabs. Both the main slab and the counter slab contain remains of fossilized, crushed bones and their imprints; individual bones are partly or completely buried in the matrix (Fig. 1). It was discovered during a paleobotanical excavation, organized by the Department of Palaeontology from the University of Vienna, near the village of Schaßbach, about $50 \mathrm{~km}$ northeast of Klagenfurt in the Lavanttal, Carinthia, southern Austria. GPS coordinates using WGS 84 datum: $46.79752^{\circ} \mathrm{N} 14.80676^{\circ} \mathrm{E}$ at an altitude of $471 \mathrm{~m}$ above sea level. The specimen is dated to the Upper Sarmatian (upper Middle Miocene), ca $12 \mathrm{Ma}$. It was found in freshwater sediments that contain two coal seams lying above the Middle Sarmatian layers (Reischenbacher et al. 2007).

Taxonomic remarks. The specimen is distinguished from non-passerine taxa by the combination of the following characters: sternum with only one pair of incisions, the incisurae laterales; coracoid with a well-pronounced and hooked processus acrocoracoideus; humerus with a prominent processus flexorius that protrudes far distally; ulna with prominent olecranon; carpometacarpus with processus intermetacarpalis, processus dentiformis and a broad distal end of the os metacarpale minus that protrudes far distally; 


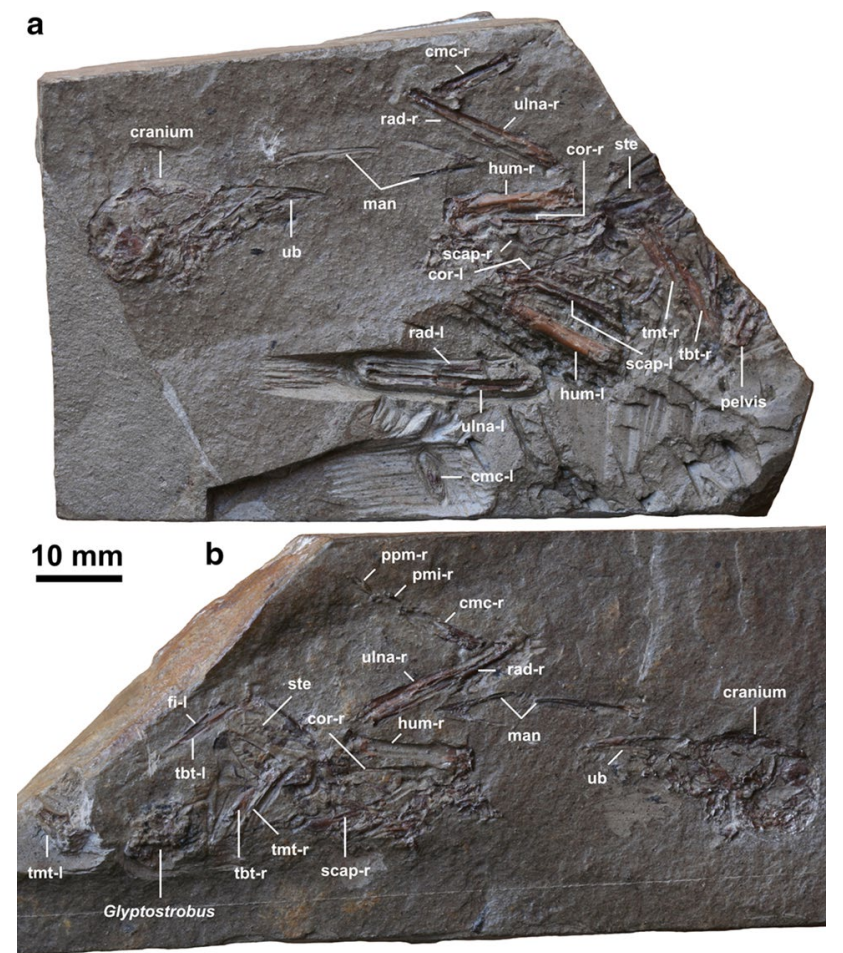

Fig. 1 Passerine bird LMK-Pal 7.451a+b from Schaßbach, Carinthia, southern Austria, Upper Sarmatian (upper Middle Miocene), ca 12 Ma. a Main slab; b counter slab. Left $(-l)$ and right $(-r)$ elements are indicated. Abbreviations: $c m c$ carpometacarpus, cor coracoid, $f i$ fibula, hum humerus, man mandibula, pmi phalanx digiti minoris, ppm phalanx proximalis digiti majoris, rad radius, scap scapula, ste sternum, $t b t$ tibiotarsus, $t m t$ tarsometatarsus, $u b$ upper beak

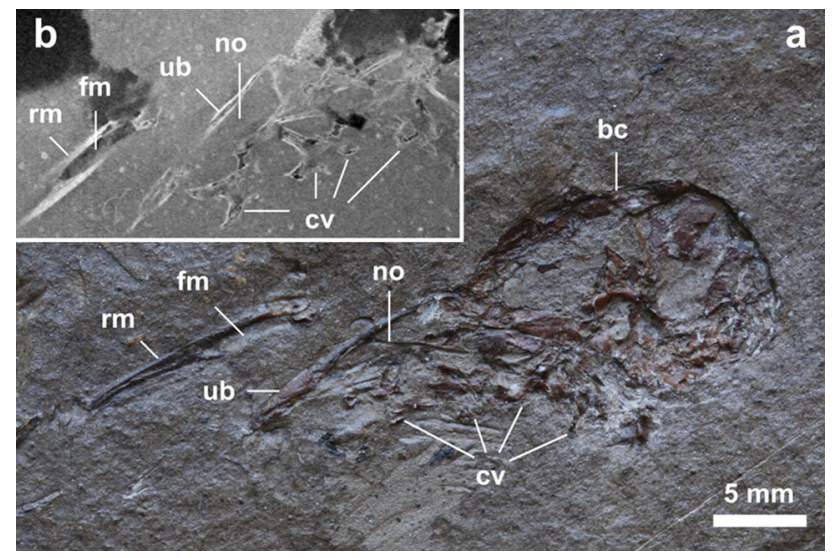

Fig. 2 Passerine bird LMK-Pal 7.451a+b from Schaßbach, Carinthia, southern Austria, Upper Sarmatian (upper Middle Miocene), ca 12 Ma. a Photograph of the head, counter slab; b micro-CT scan of the head, counter slab. Abbreviations: $b c$ braincase, $c v$ cervical vertebrae, $f m$ fenestra mandibulae, no narial opening, $r m$ ramus mandibulae, $u b$ upper beak

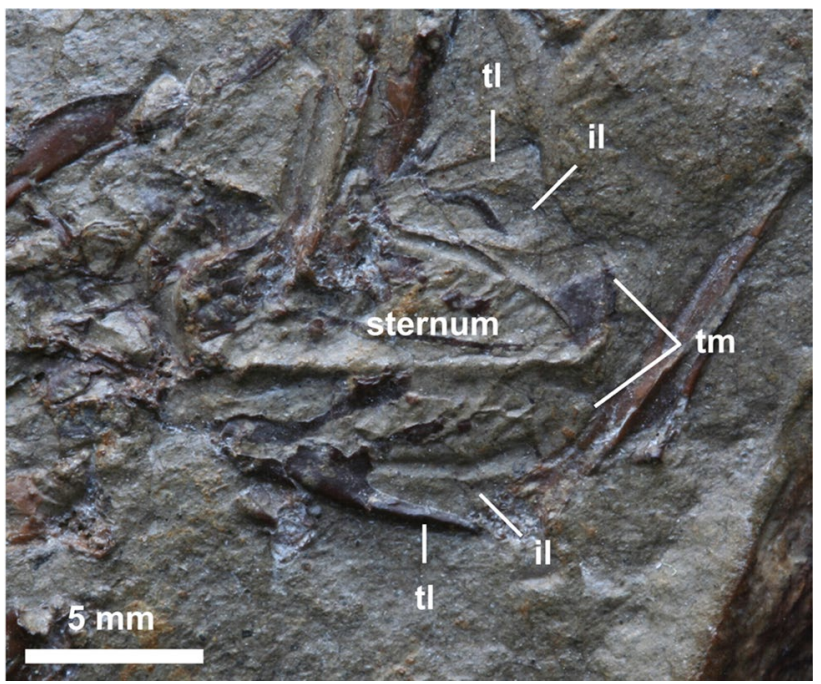

Fig. 3 Sternum of a passerine bird LMK-Pal 7.451a + b from Schaßbach, Carinthia, southern Austria, Upper Sarmatian (upper Middle Miocene), ca $12 \mathrm{Ma}$, counter slab, ventral view. Abbreviations: il incisura lateralis, $t l$ trabecula lateralis, $t m$ trabecula mediana

tarsometatarsus with proximo-distally short hypotarsus and trochleae of the second, third and fourth toes arranged in a line.

Description and comparison. Measurements (maximum length in millimeters, taken from the main slab (A) or counter slab (B), and left or right bone whichever was better preserved): skull, from tip of beak to posterior end of braincase, 28.9 (slab B); upper beak, 12.6 (slab A); coracoid, 14.3 (left, A); humerus, 16.6 (right, A); ulna, 20.6 (right, B); radius, 19.2 (right, B); carpometacarpus, 11.4 (right, B); tibiotarsus, \pm 29.0 (left, B). The main long bones are comparable in length to those of small passerines, such as Parus major (great tit), Sylvia atricapilla (blackcap) or Erithacus rubecula (robin).

The skull-is visible in lateral view; both slabs contain bone debris and their imprints (Figs. 1,2). The upper beak appears flat and its length is slightly smaller than the length of the braincase. The narial opening is cucumber-shaped and occupies about half the length of the entire upper beak. The lightly built mandibula is fractured and dislocated from the cranium. The symphysis mandibulae is visible in dorsal view, a broken off right ramus mandibulae in medial view, whereas the left ramus mandibulae from the angulus mandibulae to the articular part is missing. The preserved fragment of the fenestra mandibulae (Fig. 2) indicates that the entire fenestra was large as in extant Oscines; according to Mayr and Manegold (2006a) this fenestra is small in Acanthisittidae and most Suboscines. The articular end is too poorly preserved for meaningful comparison. In terms 

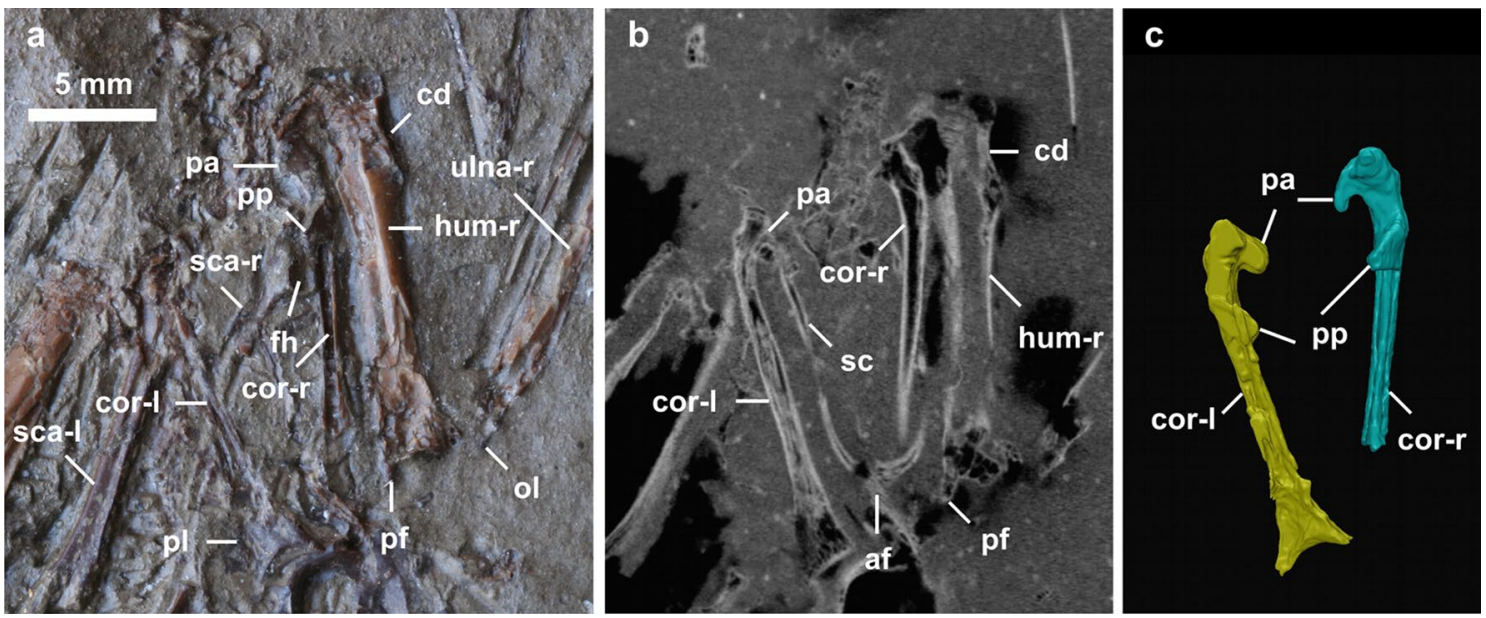

Fig. 4 Passerine bird LMK-Pal 7.451a +b from Schaßbach, Carinthia, southern Austria, Upper Sarmatian (upper Middle Miocene), ca $12 \mathrm{Ma}$. Shoulder girdle and proximal wing, main slab. a Photograph, b micro-CT scan, $\mathbf{c}$ reconstruction of coracoids based on micro-CT scans. Left $(-l)$ and right $(-r)$ elements are indicated. Abbreviations:

of size, relatively delicate structure and general appearance, the beak resembles the beak of extant representatives of such genera as Locustella, Acrocephalus, Sylvia or Erithacus, but the state of its preservation precludes more detailed comparisons.

The vertebrae - are poorly preserved and partly buried in the sediment, so the boundaries between them are difficult to determine and it is also difficult to distinguish their minor morphological features. However, it is apparent that not all of them are in their normal anatomical position. A dozen or so presacral vertebrae in two segments of several vertebrae can be distinguished: under the skull and between coracoids; some other vertebrae are scattered in different places on both slabs. Neither the notarium nor any caudal vertebrae can be seen.

The sternum - the cranial part of the sternum is visible on the main slab in dorsal view, and the entire sternum in ventral view on the counter slab. No details in the cranial part can be seen, while the caudal part has been preserved well (Fig. 3). As in most Passeriformes, in the caudal part of the sternum there is only one pair of incisions, the incisurae laterales, while almost all non-passerine small arboreal birds closely related to Passeriformes (Coliiformes, Piciformes, Coraciiformes) have a four-notched sternum (Feduccia and Olson 1982). The caudal edge of the trabecula mediana is wide. The trabecula lateralis does not protrude beyond the corpus sterni.

The furcula-is completely embedded in sediment on the main slab and only visible in the micro-CT scans (Fig. 4). af apophysis furculae, $c d$ crista deltopectoralis, cor coracoid, $f h$ facies articularis humeralis, hum humerus, ol olecranon, $p a$ processus acrocoracoideus, $p f$ processus flexorius, $p l$ processus lateralis, $p p$ processus procoracoideus, $s c$ scapus claviculae, $s c a$ scapula

As in Passeriformes, the bone is U-shaped, the scapus claviculae is slender, and it appears that the apophysis furculae bears a median projecting knob or blade.

Both coracoids - partially covered by matrix, are positioned with their dorsal sides up on the main slab. The left coracoid is complete, while the right one is missing its sternal end (Fig. 4). Micro-CT scans allow us to see details more clearly. As in extant Passeriformes, the coracoid is long and narrow and the processus acrocoracoideus is well pronounced and hooked. As in extant small passerines, the cranialmost tip of the processus acrocoracoideus is shifed medially beyond the medial edge of the shaft which differs from the condition observed in the late Miocene Sylvosimadaravis [Cerhia] janossyi whose tip of the processus acrocoracoideus is situated in the midline of the shaft (Zelenkov 2017).The processus procoracoideus is moderately enlarged and thus differs from both the greatly reduced process of the extant Accanthisittidae and most Oscines as well as from the much larger process of some extant Suboscines (see Mayr and Manegold 2006a). It should be noted, however, that the processus procoracoideus in some extant Oscines, e.g., Bombycilla garrulus, is also somewhat enlarged. A similar sized processus procoracoideus is observed in the Pliocene Carduelis medius from Hungary, and somewhat smaller but also enlarged processes are in several other passerines (e.g., Anthus baranensis, Bombycilla brevia, Sturnus brevis or Carduelis kretzoii) from the Late Miocene and Pliocene of Hungary (Kessler 2013). The processus lateralis of the sternal end is greatly reduced as in all extant passerines. The dorsal surface of the shaft splintered off and now the inside surface of the ventral side of the bone is visible. Therefore, the shaft appears to be 

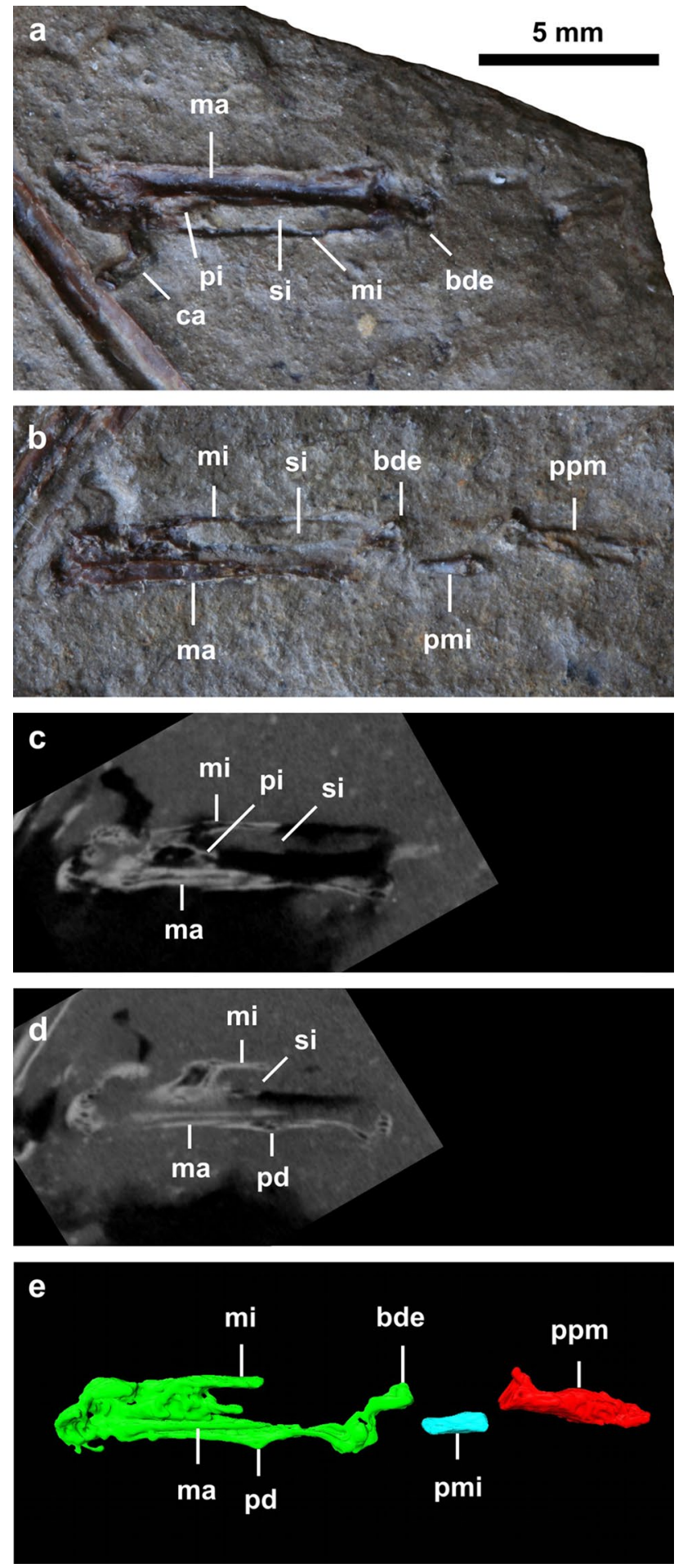

Fig. 5 Passerine bird LMK-Pal 7.451a+b from Schaßbach, Carinthia, southern Austria, Upper Sarmatian (upper Middle Miocene), ca 12 Ma. Distal end of right wing with the carpometacarpus and some phalanges. a Photograph of the main slab; $\mathbf{b}$ photograph of the counter slab, $\mathbf{c}-\mathbf{d}$ microCT scans of the counter slab; e reconstruction based on micro-CT scans. Note that not all structures are visible on a single scan. Abbreviations: bde broad distal end (of os metacarpale minus), $c a$ os carpi ulnare, pmi phalanx digiti minoris, $m a$ os metacarpale majus, $m i$ os metacarpale minus, $p d$ processus dentiformis, $p i$ processus intermetacarpalis, $p p m$ phalanx proximalis digiti majoris, si spatium intermetacarpale

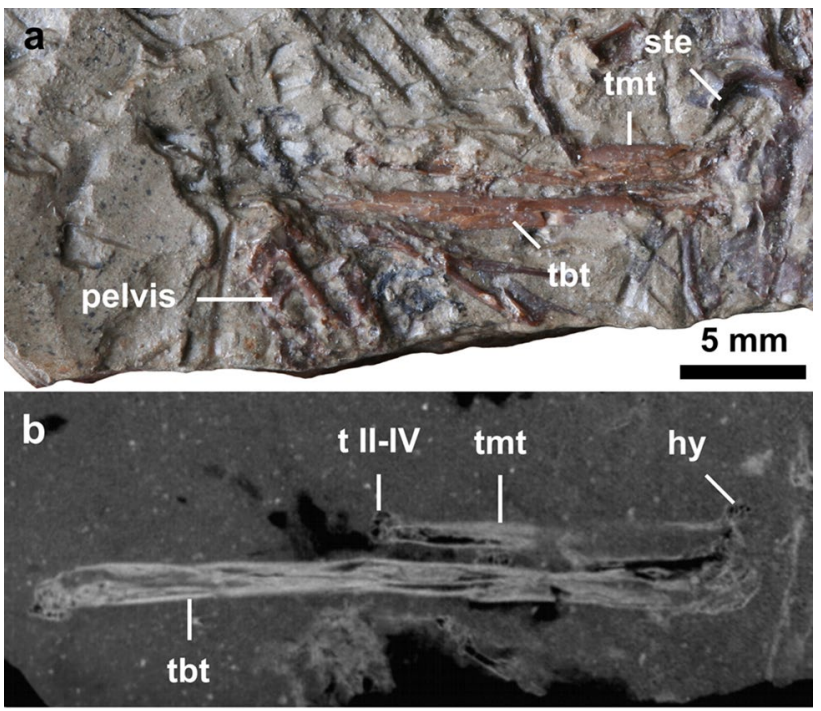

Fig. 6 Right leg bones of a passerine bird LMK-Pal 7.451a + b from Schaßbach, Carinthia, southern Austria, Upper Sarmatian (upper Middle Miocene), ca 12 Ma. a Photograph of the main slab, b microCT scan of the main slab. Abbreviations: hy hypotarsus, ste sternum, $t I I-I V$ trochleae metatarsi II-IV, $t b t$ tibiotarsus, $t m t$ tarsometatarsus

a narrow groove, which clearly shows the pneumatisation of the avian coracoid.

The scapula - as in other Passeriformes, the corpus scapulae is blade-like, almost straight along its entire length. A roundish and slightly concave facies articularis humeralis protrudes from the matrix (Fig. 4). The acromion is partly covered by sediment and does not reveal any meaningful details.

The right humerus - is mostly preserved but divided unevenly on the two slabs (Fig. 4). On the main slab it is visible in caudal view, it only lacks the surface of the bone in the proximal and distal parts. On the counter slab there is mainly an imprint of the caudal surface of the humerus, and bone remains from the proximal and distal parts. The left humerus is much more damaged; preserved is only its shaft on the main slab, but not the proximal and distal parts. No details can be seen in the proximal part. The shaft of the humerus is almost straight and very stout. A relatively thick shaft was also present in Regulus pliocenicus and Emberiza media from the Pliocene (Kessler 2013: pls. XIV, XXVI). The crista deltopectoralis is relatively long and reaches up to about one third of the total length of the humerus. The processus flexorius is prominent and reaches far distally, as in extant Passeriformes. As in Passeriformes, the distal end widens especially towards the dorsal side; the processus supracondylaris distalis cannot be seen but is probably still buried in the matrix. 
Both ulnae - are visible in dorsal view on the main slab, but they are heavily splintered and fragmented. On the counter slab only the right ulna is preserved. As in Passeriformes, the bone is slender and slightly longer than the humerus, and the prominent olecranon is extended proximally and tapers (Fig. 4). The papillae remigiales caudales are not visible, indicating that they were either missing or small, which also agrees with Passeriformes.

The radius - is too poorly preserved to allow reliable comparison.

The right carpometacarpus - is visible on both slabs (Fig. 5) and the left one-largely buried in matrix-only on the main slab. Some of the details can only be seen in microCT scans. As in extant Passeriformes, the os metacarpale minus is parallel to the os metacarpale majus, the spatium intermetacarpale is narrow, and the processus intermetacarpalis reaches to the os metacarpale minus (Fig. 5a, b). A well-developed processus dentiformis is visible on the cranial margin of the bone (Fig. 5c), which is typical of the extant Acanthisittidae and most Passeriformes (see Pocock 1966; Mourer-Chauviré 1989). As in extant Oscines, the distal end of the os metacarpale minus is broad, rectangular and protrudes far distally.

Other elements of the wing-as in extant Oscines, the phalanx proximalis digiti majoris (reconstructed from micro-CT scans of the main slab and counter slab) is relatively long and rather narrow (Fig. 5b, e); in Suboscines it is broad and cleaver-shaped (Mayr and Manegold 2006b; Riamon et al. 2020). The right os carpi ulnare is well preserved on the main slab and imprinted on the counter slab; the left bone is completely embedded in sediment on the main slab and visible only in micro-CT scans. The os carpi radiale and other wing phalanges are too poorly preserved and/or buried in matrix to allow meaningful comparison.

The pelvis-visible only on the main slab, is largely incomplete and partly covered with sediment, which makes morphological features difficult to discern (Fig. 6). The preserved remains indicate that it was small, as in extant Passeriformes. The visible fragment of the synsacrum indicates that the pelvis is oriented with its ventral side up, which means that it is flipped over 180 degrees relative to its anatomical position and other skeletal elements. On the counter slab, where the pelvis would be expected, there is a relatively large fructification of Glyptostrobus sp.

The femur-neither the right nor the left femur is preserved.

Both tibiotarsi-are largely covered by sediment and fully visible only in the micro-CT scans. The partially complete left tibiotarsus is visible on the counter slab and the right one on the main slab (Fig. 6). Both bones articulate with the tarsometatarsi but are detached from the rest of the body. Minor morphological details are not discernable but one can see that the tibiotarsus is slender and straight and is clearly the longest skeletal element, as in extant Passeriformes. The fibula reaches distally about half the length of the tibiotarsus.

The tarsometatarsus - fragments of the right tarsometatarsus are visible on both slabs, and the proximal part of the left bone only on the counter slab; both bones are partially covered with sediment and thus better recognizable in micro-CT scans (Fig. 6). As in extant Passeriformes, the tarsometatarsus is slender, the hypotarsus is short proximo-distally and the trochleae metatarsi II, III and IV reach equally far distally and are arranged in one plane dorso-ventrally.

Most of the preserved skeletal elements are in articulation with adjacent bones. However, there are a few exceptions. Within the cranial material, the mandible is separated from the rest of the skull, and the quadratum has been displaced and is now situated within the orbit. The vertebrae between the pelvis and the skull do not form an intact vertebral column but are also partly displaced. The left ulna and left radius are disarticulated from the left humerus but have not been dislocated much. The largest changes in position can be seen within the pelvic girdle and legs. The pelvis is not only dislocated from its natural location but also turned over. Both femora are missing, and the rest of the legs (tibiotarsus and tarsometatarsus) are disarticulated and dislocated from the rest of the body. No damage (perforations, holes, bitemarks, scratches, etc.) was observed on the bone surface that could be attributed to the activity of predators or scavengers.

\section{Specimen \# LMK-Pal 7.452}

Figure 7

Preservation and provenance. An isolated complete sternum, preserved on a claystone slab, found near the village of Schaßbach, about $50 \mathrm{~km}$ northeast of Klagenfurt in the Lavanttal, Carinthia, southern Austria; dated to the Upper Sarmatian (upper Middle Miocene), ca 12 Ma. GPS coordinates using WGS 84 datum: $46.79752^{\circ} \mathrm{N} 14.80676^{\circ} \mathrm{E}$ at an altitude of $471 \mathrm{~m}$ above sea level.

Description. The sternum is exposed in dorsal view (Fig. 7). Its proportions and individual features clearly indicate that it belongs to Passeriformes. In particular, the sternum is long and relatively narrow; the processes craniolaterales are long and protrude further anterior than the labrum dorsale; the spina externa is elongated and bifurcated; there is only one pair of incisions, the incisurae laterales in the posterior part of the sternum; the trabeculae laterales widen at the end 


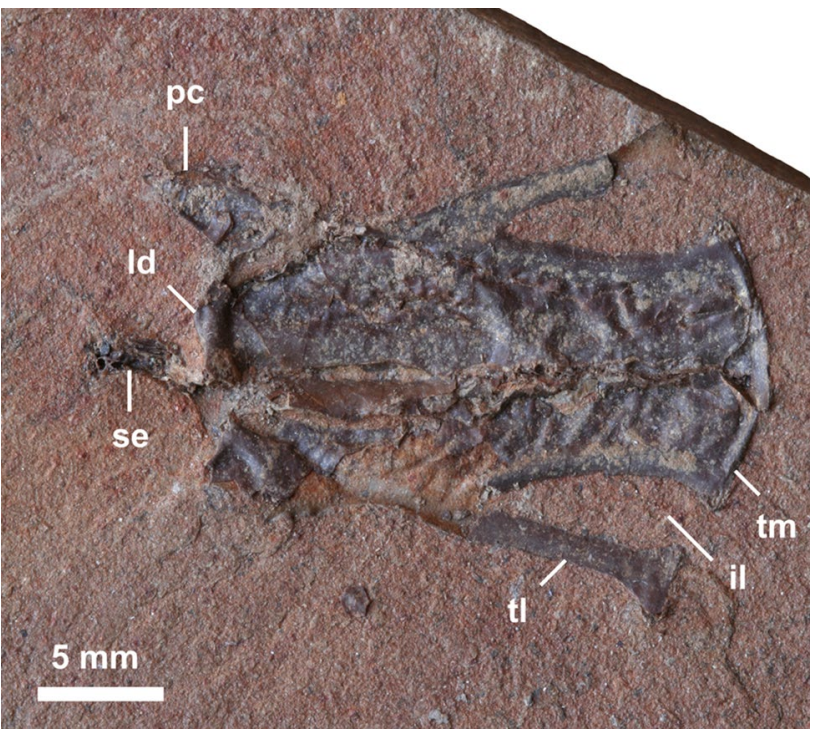

Fig. 7 Sternum of a passerine bird LMK-Pal 7.452 from Schaßbach, Carinthia, southern Austria, Upper Sarmatian (upper Middle Miocene), ca 12 Ma. Abbreviations: il incisura lateralis, ld labrum dorsale, $p c$ processus craniolateralis, se spina externa, $t l$ trabecula lateralis, $t m$ trabecula mediana

and do not reach as far caudally as the corpus sterni; and the trabecula mediana widens in the caudal part.

Remarks. Extant Passeriformes differ in size and appearance of the sternum. Most of them can be excluded, because their sternum is clearly smaller and/or is relatively wider. Corpus sterni of similar size and proportions occur, for example, in Cyanopica, Melanocorypha, Coccothraustes, or small representatives of the genus Turdus. However, other details such as the shape of processes craniolaterales, rostrum sterni and/or distal tips of trabecula laterales are different in these taxa. Because the specimen is flattened and we do not know all the morphological details, it is difficult to clearly assign it even to an extant family. In addition, it cannot be assigned to any known fossil taxon, because the sternum extremely rarely preserves well enough in the fossil record and there is no fossil material available to compare our specimen with.

\section{Discussion}

The specimens studied here are the oldest passerines discovered in present-day Austria. They give further clues on the morphological diversity of Austrian passerine birds in the Middle Miocene representing birds of two different size classes: small thrush-sized (isolated sternum) and sylvid-sized (articulated remains). These finds are not unexpected; the remains of birds of similar size were found at various Miocene sites in Europe (Mlíkovský 2002; Kessler 2013). However, the currently described specimens fill a gap in the paleobiogeographic distribution of passerines, and the partly articulated specimen and the complete sternum provide unique information on skeletal element proportions of the middle Miocene passerines. Such data can be helpful in identifying and correlating isolated bones from other localities.

The preserved osteological features, including the large fenestra mandibulae, the wide distal end of the os metacarple minus, and the long and narrow phalanx proximalis digiti majoris, indicate that the specimen represents an oscine passerine. It is known that Oscines and Suboscines coexisted in Europe in the Late Oligocene and Early Miocene (Ballmann 1969; Manegold 2008a; Mayr 2013), but from later periods only the remains of Oscines are recorded.

Regardless of its systematic position, the size and general similarity of the beak to that of extant representatives such as Locustella, Acrocephalus, Sylvia or Erithacus suggest that LMK-Pal 7.451a + b fed mainly on small invertebrates although it could also take small soft fruit, just like extant members of some of the above mentioned genera do (del Hoyo et al. 2005, 2006).

Although some skeletal elements including the mandible, vertebrae, legs and to some degree also the left wing are disarticulated, the majority of the skeleton is preserved in articulation. The preservation of the fossil in such an associated condition suggests that it was relatively quickly covered by sediment after death (Schäfer 1972). In this respect, LMK-Pal 7.451a $+\mathrm{b}$ resembles Oligocene specimens of birds and fishes from the Carpathians (Bochenski et al. 2011, 2013, 2018). However, LMK-Pal 7.451a + b is more disarticulated than the Oligocene specimens: the legs separated from the torso and would have probably been lost, had the entire specimen not been buried quickly by sediment. This indicates that the specimen was somewhat longer exposed to natural decomposition factors, including the formation of putrefaction gases, which usually cause under-representation of avian leg bones (Ericson 1987).

This study is an example of the successful application of micro-CT scanning to fossil bird research. The condition of the specimen did not allow for its better preparation from the rock matrix, but the fragments of the skeleton hidden in the matrix could be seen on scans and reconstructed. As technology progresses, micro-CT scanning can be expected to become the standard additional procedure when required.

Acknowledgements The study was partly funded by NERC grants NE/ L002434/1 and NE/P013724/1 to A.E. Additional funding and support were provided by the Reptilienzoo Happ Ges. M.b.H. Thanks are due to Nikita Zelenkov (Borissiak Paleontological Institute RAS) and an anonymous reviewer for their valuable comments that improved the manuscript.

Open Access This article is licensed under a Creative Commons Attribution 4.0 International License, which permits use, sharing, adaptation, distribution and reproduction in any medium or format, as long as you give appropriate credit to the original author(s) and the source, 
provide a link to the Creative Commons licence, and indicate if changes were made. The images or other third party material in this article are included in the article's Creative Commons licence, unless indicated otherwise in a credit line to the material. If material is not included in the article's Creative Commons licence and your intended use is not permitted by statutory regulation or exceeds the permitted use, you will need to obtain permission directly from the copyright holder. To view a copy of this licence, visit http://creativecommons.org/licenses/by/4.0/.

\section{References}

Ballmann, P. 1969. Die Vögel aus der altburdigalen Spaltenfüllung von Wintershof (West) bei Eichstätt in Bayern. Zitteliana 1: 5-60.

Baumel, J.J., and L.M. Witmer. 1993. Osteologia. In Handbook of Avian Anatomy: Nomina Anatomica Avium, eds. J.J. Baumel, A.S. King, J.E. Breazile, H.E. Evans, and J.C. Vanden Bergen, 45-132. Cambridge, Mass.: Nuttall Ornithological Club.

Bochenski, Z.M., T. Tomek, M. Bujoczek, and K. Wertz. 2011. A new passerine bird from the early Oligocene of Poland. Journal of Ornithology 152: 1045-1053. https://doi.org/10.1007/ s10336-011-0693-2.

Bochenski, Z.M., T. Tomek, K. Wertz, and E. Swidnicka. 2013. The third nearly complete passerine bird from the early Oligocene of Europe. Journal of Ornithology 154: 923-931. https://doi. org/10.4202/app.2012.0021.

Bochenski, Z.M., T. Tomek, and E. Swidnicka. 2014a. The first complete leg of a passerine bird from the early Oligocene of Poland. Acta Palaeontologica Polonica 59: 281-285. https://doi.org/10. 4202/app.2012.0021.

Bochenski, Z.M., T. Tomek, and E. Swidnicka. 2014b. A complete passerine foot from the late Oligocene of Poland. Palaeontologia Electronica 17.1.6A: 1-7. https://doi.org/10.26879/431

Bochenski, Z.M., T. Tomek, K. Wertz, J. Happ, M. Bujoczek, and E. Swidnicka. 2018. Articulated avian remains from the early Oligocene of Poland adds to our understanding of Passerine evolution. Palaeontologia Electronica 21.2.32A: 1-12. https:// doi.org/10.26879/843

Bochenski, Z.M., T. Tomek, M. Bujoczek, and G. Salwa. 2021. A new passeriform (Aves: Passeriformes) from the early Oligocene of Poland sheds light on the beginnings of Suboscines. Journal of Ornithology. https://doi.org/10.1007/s10336-021-01858-0.

Boev, Z. 2007. Neogene avifaunas of Bulgaria (a brief review). In Evolution and Ecology, eds. N. Bakardjieva, S. Chankova, B. Krastanov, and S. Gateva, 26-35. Sofia: Union of the Scientists of Bulgaria. ( $=3^{\text {rd }}$ National Seminar, Proceedings).

del Hoyo, J., A. Elliott, and D.A. Christie, eds. 2006. Handbook of the birds of the world (Vol. 11). Old World flycatchers to Old World warblers. Barcelona: Lynx Edicions.

Ericson, P.G. 1987. Interpretations of archaeological bird remains: A taphonomic approach. Journal of Archaeological Science 14 (1): $65-75$

Feduccia, A., and S.L. Olson. 1982. Morphological similarities between the Menurae and the Rhinocryptidae, relict passerine birds of the southern hemisphere. Smithsonian Contributions to Zoology 366: 1-22.

Gál, E., and E. Kessler. 2006. Songbird remains from the Miocene (Middle Sarmatian) site Credinţa (Dobrogea, South-East Romania). In Volume dedicated to Dan Grigorescu on his 65th birthday, ed. Z. Csiki, 117-125. Bucharest: University of Bucharest Printing House.

Grímsson, F., J.M. Bouchal, A. Xafis, and R. Zetter. 2015. Combined LM and SEM study of the middle Miocene (Sarmatian) palynoflora from the Lavanttal Basin, Austria: Part V. Magnoliophyta
3-Myrtales to Ericales. Grana 54(2): 1-67. https://doi.org/10. 1080/00173134.2015.1007081

Hír, J., J. Kókay, M. Venczel, E. Gál, and E. Kessler. 2001. Előzetes beszámoló a felsőtárkányi „Güdör-kert” n. őslénytani lelőhelykomplex újravizsgálatáról. Folia Historico Naturalia Musei Matraensis 25: 41-64.

Hoyo, J.D., A. Elliot, and D.A. Christie. 2005. Handbook of the Birds of the World (Volume 10): Cuckoo-shrikes to Thrushes. Barcelona, Spain: Lynx Editions.

Kessler, E. 2013. Neogene songbirds (Aves, Passeriformes) from Hungary. Hantkeniana 8: 37-149.

Kessler, E., and H. János. 2012. The avifauna in North Hungary during the Miocene. Part II. Bulletin of the Hungarian Geological Society 142(2): 149-168.

Kessler, E., and M. Venczel. 2009. Bird remains from the Middle Miocene of Subpiatră (W-Romania). Nymphaea, Folia Naturae Bihariae 36: 27-36.

Manegold, A. 2008a. Passerine diversity in the late Oligocene of Germany: Earliest evidence for the sympatric coexistence of Suboscines and Oscines. Ibis 150: 377-387. https://doi.org/10. 1111/j.1474-919X.2008.00802.x.

Manegold, A. 2008b. Earliest fossil record of the Certhioidea (treecreepers and allies) from the early Miocene of Germany. Journal of Ornithology 149(2): 223-228. https://doi.org/10. 1007/s10336-007-0263-9.

Manegold, A., G. Mayr, and C. Mourer-Chauviré. 2004. Miocene songbirds and the composition of the European passeriform avifauna. The Auk 121(4): 1155-1160.

Mayr, G. 2013. The age of the crown group of passerine birds and its evolutionary significance-molecular calibrations versus the fossil record. Systematics and Biodiversity 11(1): 7-13. https:// doi.org/10.1080/14772000.2013.765521.

Mayr, G., and A. Manegold. 2004. The oldest European fossil songbird from the early Oligocene of Germany. Naturwissenschaften 91: 173-177. https://doi.org/10.1007/s00114-004-0509-9.

Mayr, G., and A. Manegold. 2006a. New specimens of the earliest European passeriform bird. Acta Palaeontologica Polonica 51 (2): 315-323.

Mayr, G., and A. Manegold. 2006b. A small suboscine-like passeriform bird from the early Oligocene of France. The Condor 108 (3): 717-720. https://doi.org/10.1093/condor/108.3.717.

Mlíkovský, J. 2002. Cenozoic Birds of the World: Europe. Part 1. Prague: Ninox Press.

Mourer-Chauviré, C. 2006. The avifauna of the Eocene and Oligocene Phosphorites du Quercy (France): An updated list. Strata Série 1(13): 135-149.

Mourer-Chauviré, C., M. Hugueney, and P. Jonet. 1989. Découverte de Passeriformes dans l'Oligocène supérieur de France. Comptes Rendus De L'académie Des Sciences (II) 309: 843-849.

Mourer-Chauviré, C., D. Berthet, and M. Hugueny. 2004. The late Oligocene birds of the Créchy quarry (Allier, France), with a description of two new genera (Aves: Pelecaniformes: Phalacrocoracidae, and Anseriformes: Anseranatidae). Senckenbergiana Lethaea 84: 303-315. https://doi.org/10.1007/BF03043473.

Nolf, D., and R. Brzobohatý. 2009. Lower Badenian fish otoliths of the Styrian and Lavanttal basins, with a revision of Weinfurter's type material. Annalen des Naturhistorischen Museums in Wien (A:) 111: 323-356.

Pocock, T.N. 1966. Contributions to the osteology of African birds. Ostrich 37 (suppl. 1): 83-94.

Prieto, J., A. Hassler, and M. Gross. 2019. Ein seltenes Fossil eines Stachelbilches aus Kärnten. Carinthia (II) 209/129: 581-586.

Reischenbacher, D., H. Rifelj, R.F. Sachsenhofer, B. Jelen, S. Coric, M. Gross, and B. Reichenbacher. 2007. Early Badenian paleoenvironment in the Lavanttal Basin (Mühldorf Formation; Austria): 
Evidence from geochemistry and paleontology. Austrian Journal of Earth Sciences 100: 202-229.

Riamon, S., N. Tourment, and A. Louchart. 2020. The earliest Tyrannida (Aves, Passeriformes), from the Oligocene of France. Scientific Reports 10: 9776. https://doi.org/10.1038/ s41598-020-66149-9.

Schäfer, W. 1972. Ecology and palaeoecology of marine environments. Chicago: The University of Chicago Press.

Volkova, N.V., and N.V. Zelenkov. 2018. A scansorial passerine bird (Passeriformes, Certhioidea) from the uppermost lower Miocene of Eastern Siberia. Paleontological Journal 52(1): 58-65. https:// doi.org/10.1134/S0031030118010148.
Wank, M. 1991. Die Fossilien von Schönweg bei St. Andrä im Lavanttal (Kärnten). Carinthia (II) 181/101: 301-313.

Zelenkov, N.V. 2018. Finds of fragmentary bird skeletons in the middle Miocene of Northern Caucasus. Doklady Biological Sciences 477(1): 223-226. https://doi.org/10.1134/S0012496617060072.

Zelenkov, N.V. 2017. The revised avian fauna of Rudabanya (Hungary, Late Miocene). In Paleontología y evolución de las Aves, eds. C. Acosta Hospitaleche, F.L. Agnolin, N. Haidr, J.I. Noriega, and C.P. Tambussi. Contribuciones del Museo Argentino de Ciencias Naturales 7: 253-266. 